\title{
Preface to 18th Nordic Symposium on Catalysis 2018
}

\author{
Anders Riisager $^{1} \cdot$ Susanne Mossin ${ }^{1} \cdot$ Jakob Munkholt Christensen ${ }^{2} \cdot$ Christian Damsgaard $^{3}$
}

Published online: 14 August 2019

(c) Springer Science+Business Media, LLC, part of Springer Nature 2019

The 18th Nordic Symposium on Catalysis was held in central Copenhagen, Denmark during the days of August 26-28, 2018 at the harbor front in the conference centre of the Engineering Organization of Denmark (IDA). The symposium was organized by researchers from the departments of Chemistry, Chemical \& Biochemical Engineering and Physics of the Technical University of Denmark (DTU), the chemistry department of the University of Copenhagen, and IDA on behalf of the Nordic Catalysis Society with Anders Riisager (DTU) serving as chair.

The 18th Nordic Symposium on Catalysis brought together about 150 researchers from 16 different countries with affiliation from academia as well as industry, and covered all aspects of catalysis from theory and modelling to applied science and engineering. 107 scientific presentations were disseminated during the symposium distributed on 51 oral contributions, 49 poster presentations, 4 invited Nordic keynote lectures, and 3 invited Plenary lectures. The international setting provided a highly inspirational forum for knowledge sharing and idea exchange, and the commitment a clear testament of the active and vibrant catalysis community in the Nordic and neighboring countries.

In the field of catalysis, many important developments and discoveries are continuously emerging and the 18 manuscripts accepted for this special issue of Topics in Catalysis highlights some of these new directions in the field.

We would like to thank all the participants, sponsors and exhibitors for making the 18th Nordic Symposium on Catalysis a very successful symposium, as well as the authors of the manuscripts in this special issue for their contributions. Special thanks also to the plenary speakers Emiel Hensen (Eindhoven University of Technology), Jan-Dierk Grunwaldt (Karlsruhe Institute of Technology), Riikka Puurunen (Aalto University, Berzelius Prize Winner 2018) for their brilliant and inspiring talks at the symposium. Moreover, we also thank the Editors of Topics of Catalysis for the opportunity to publish the special issue from the symposium and all reviewers for their contribution to the publication process.

We look forward to reconvene for the 19th Nordic Symposium on Catalysis, August 24-26, 2020 in the Helsinki sub-region of Espoo in Finland.

Publisher's Note Springer Nature remains neutral with regard to jurisdictional claims in published maps and institutional affiliations.

Anders Riisager

ar@kemi.dtu.dk

Susanne Mossin

slmo@kemi.dtu.dk

Jakob Munkholt Christensen

jamu@kt.dtu.dk

Christian Damsgaard

christian.damsgaard@ cen.dtu.dk

1 Department of Chemistry, Technical University of Denmark, Kemitorvet, Building 207, 2800 Kgs. Lyngby, Denmark

2 Department of Chemical and Biochemical Engineering, Technical University of Denmark, Søltofts Plads, Building 229, 2800 Kgs. Lyngby, Denmark

3 Department of Physics, Technical University of Denmark, Fysikvej, Building 307, 2800 Kgs. Lyngby, Denmark 